\title{
When is a Nanoparticle a Cluster? An Operando EXAFS Study of Amine Borane Dehydrocoupling by $\mathrm{Rh}_{4-6}$ Clusters.
}

John L. Fulton, Yongsheng Chen, ${ }^{\ddagger}$ Mahalingam Balasubramanian, Tom Autrey, ${ }^{\dagger}$ Nathaniel K. Szymczak, and John C. Linehan

Fundamental Science Division, Pacific Northwest National Laboratory, Richland, Washington, 99352

¥Advanced Photon Source, Argonne National Laboratory, Argonne, Illinois 60439

${ }^{\dagger}$ Chemistry Department, University of Oregon, Eugene, Oregon

\section{Page Contents:}

S2 $\quad k^{2} \chi(k)$ plots for the rhodium clusters from various amine boranes

S3 $\quad k^{2} \chi(k)$ plots for the rhodium clusters from various $\mathrm{Rh}$ precursors

S4 XAFS plots for $[\mathrm{Rh}(\operatorname{cod}) \mathrm{Cl}]_{2}$ precursor and the rhodium clusters

S5 XAFS plots for $\left[\mathrm{Rh}(\mathrm{cod})_{2}\right]$ triflate precursor and the rhodium clusters

S6 XAFS plots for $\left[\mathrm{Cp}^{*} \mathrm{RhCl}_{2}\right]_{2}$ precursor and the rhodium clusters

S7 XAFS plots for $\left[\mathrm{Rh}(\mathrm{CO})_{2} \mathrm{Cl}\right]_{2}$ precursor and the rhodium clusters

S8 XAFS plots for $\mathrm{Rh}_{6}(\mathrm{CO})_{16}$ precursor and the rhodium clusters

S9 FEFF8 fits to the $\mathrm{Rh}_{6}(\mathrm{CO})_{16}$ powder standard

$\mathrm{S} 10 \quad \mathrm{FEFF} 8$ fits to the $[\mathrm{Rh}(\mathrm{cod}) \mathrm{Cl}]_{2}$ in toluene standard

$\mathrm{S} 11$ FEFF8 fits to the $\left[\mathrm{Rh}(\mathrm{CO})_{2} \mathrm{Cl}\right]_{2}$ in toluene standard

S12 FEFF8 fits to the $\left[\mathrm{Cp} * \mathrm{RhCl}_{2}\right]_{2}$ powder standard

S13 FEFF8 fits to $\mathrm{Rh}(0)$ metal standard

S14 Example theoretical scattering calculations(FEFF8) for various $\mathrm{Rh}$ first-shell atoms ( $\mathrm{Rh}, \mathrm{Cl}, \mathrm{B})$

S15 Example theoretical scattering calculations(FEFF8) for various Rh first-shell atoms (B, N, O)) 


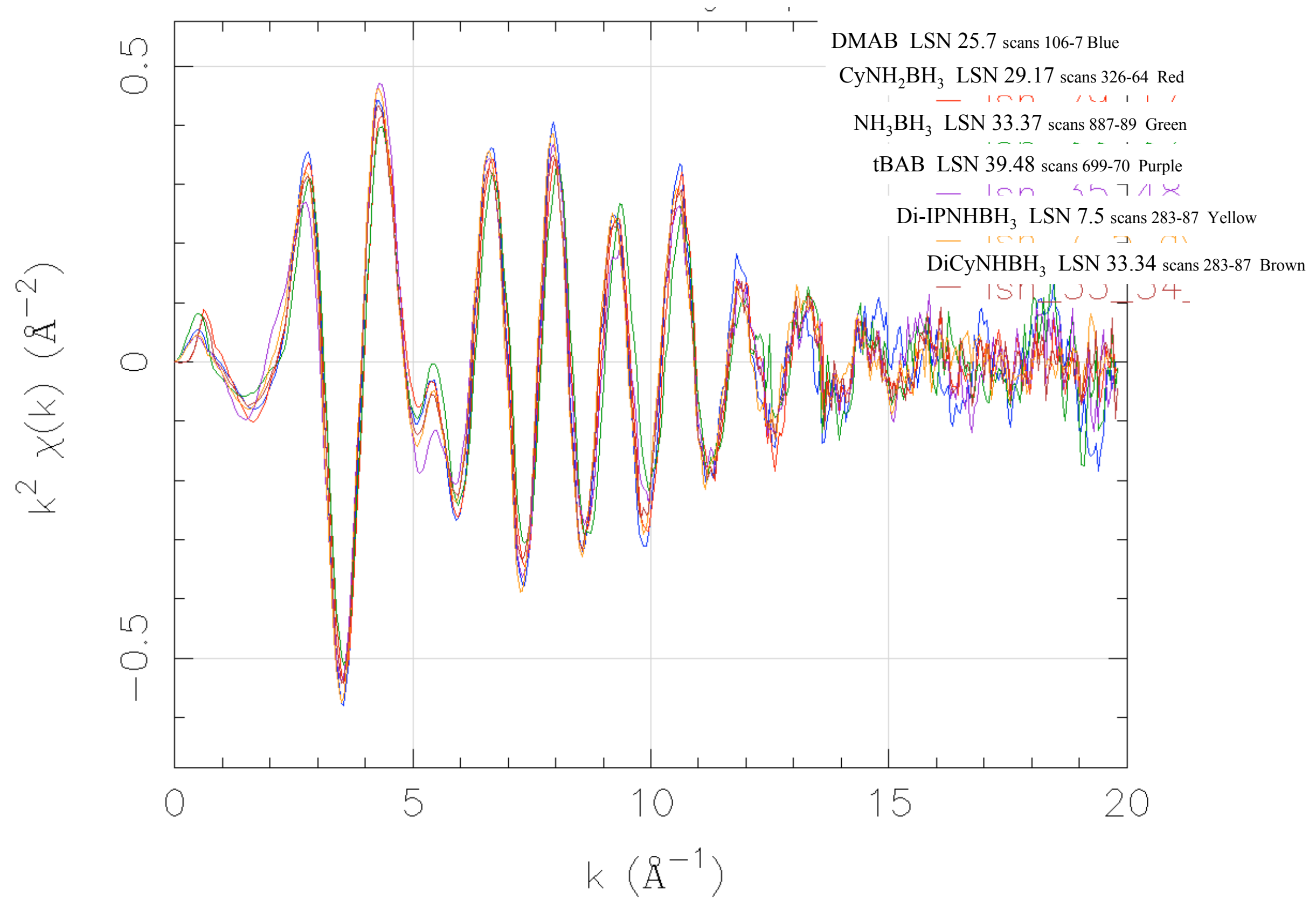

Figure S1. $k^{2} \chi(k)$ plots for the rhodium clusters from various amine boranes. The Fourier transforms of this data is used in Figure 8. 


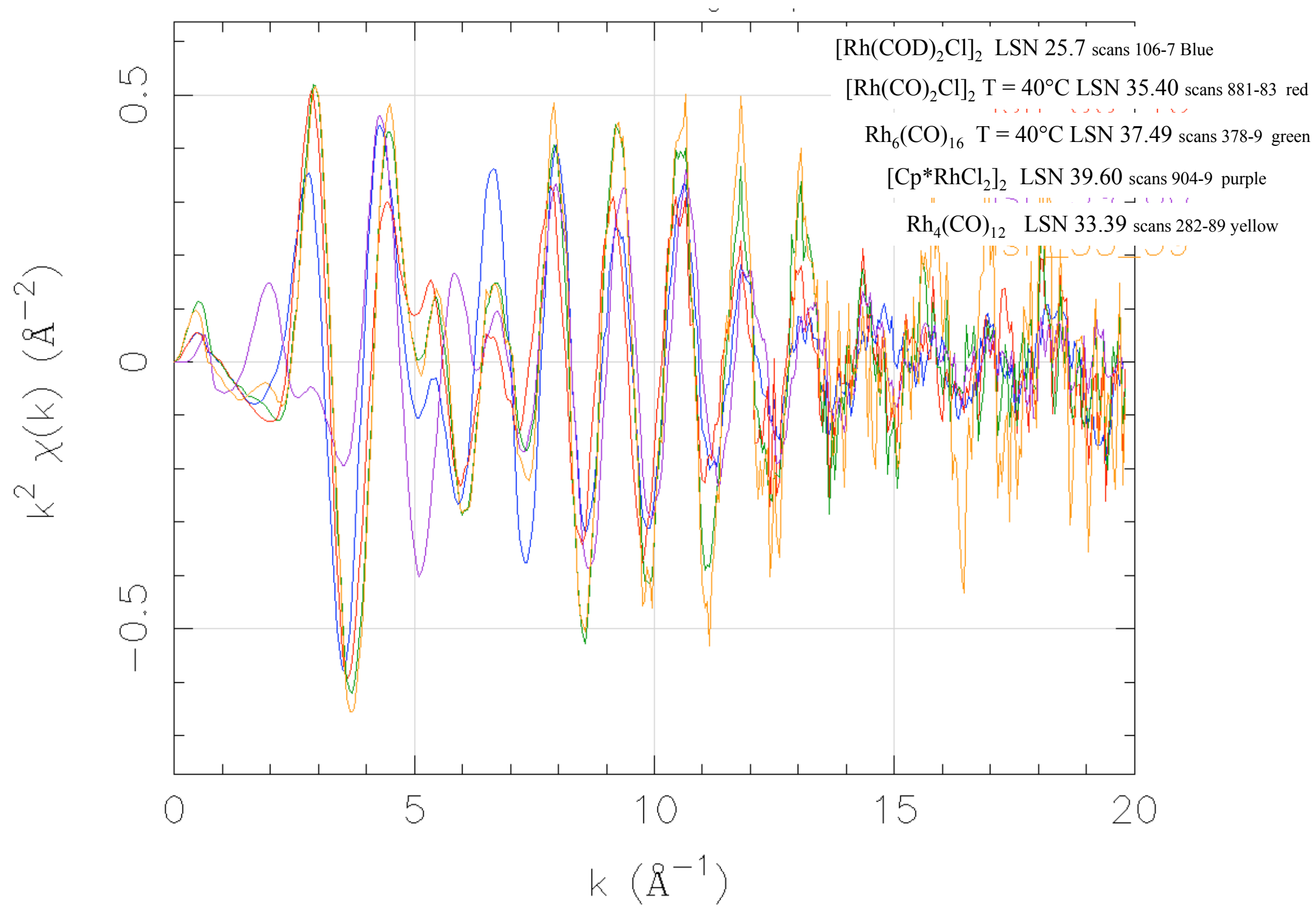

Figure S2. $k^{2} \chi(k)$ plots for the rhodium clusters from various Rh precursor compounds. The Fourier transforms of this data is used in Figure 10. 


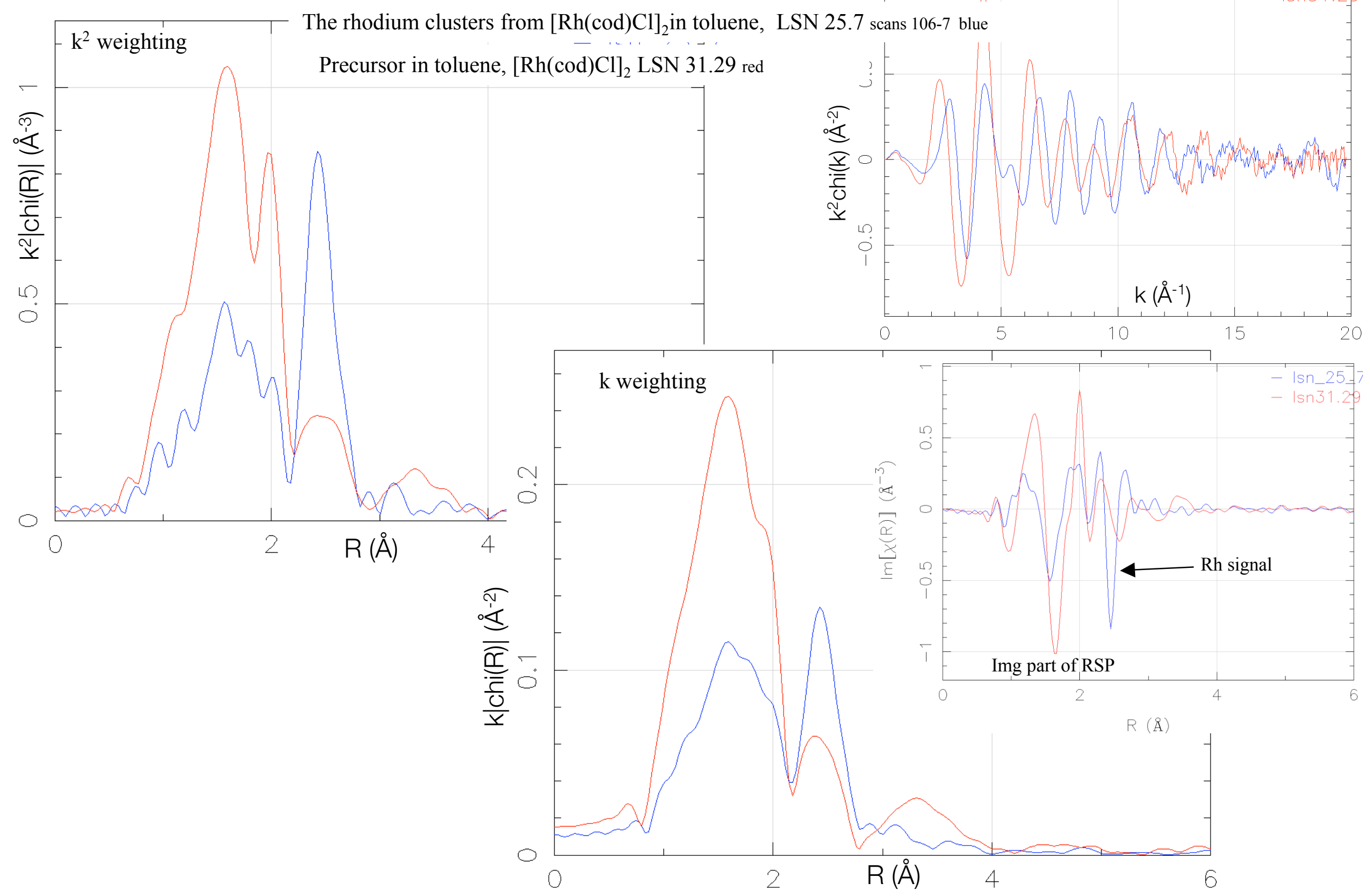

Figure S3. Various XAFS plots for $[\mathrm{Rh}(\operatorname{cod}) \mathrm{Cl}]_{2}$ in toluene and the rhodium clusters from this precursor in toluene. 


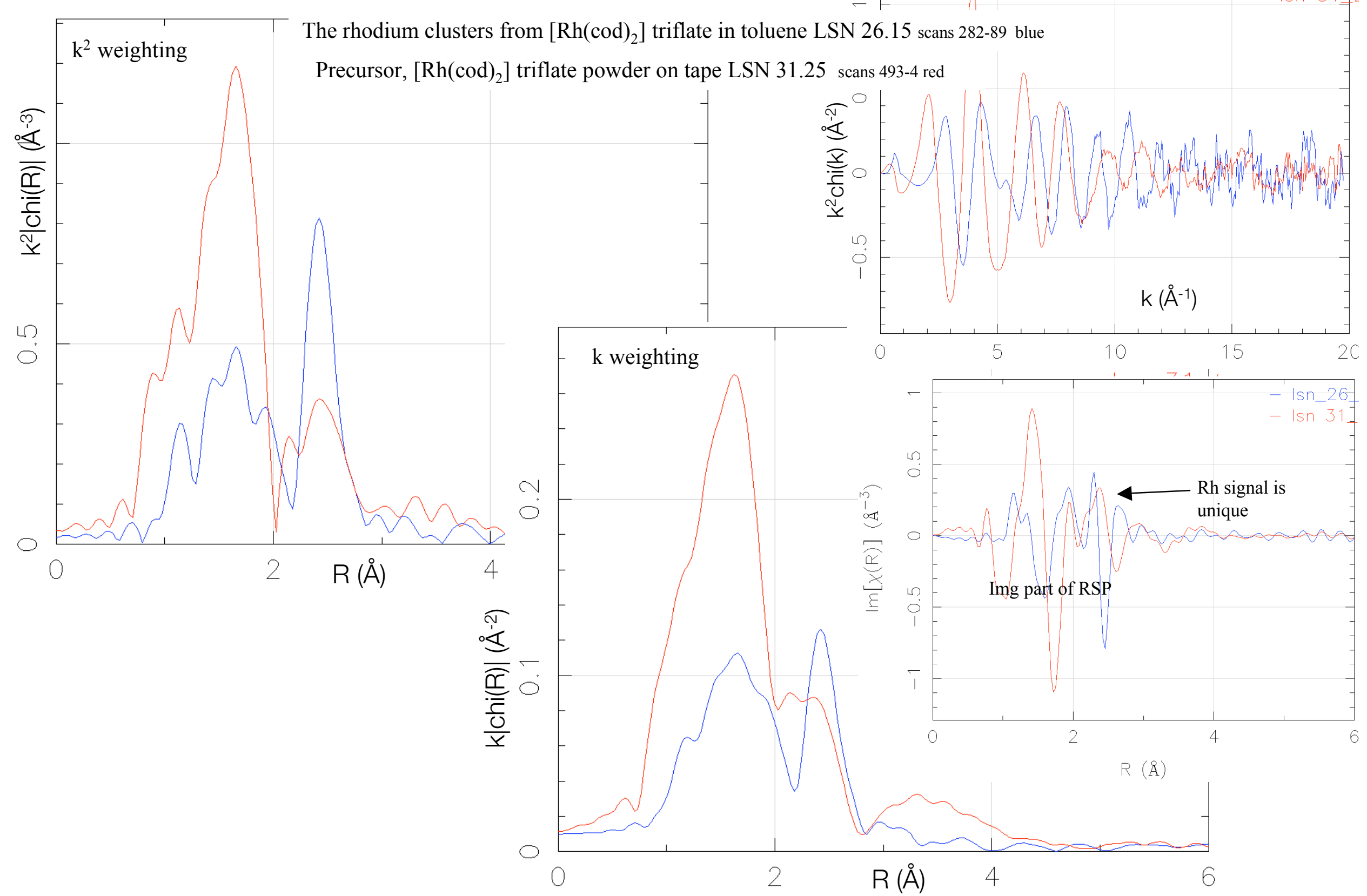

Figure S4. Various XAFS plots for $\left[\mathrm{Rh}(\operatorname{cod})_{2}\right]$ triflate powder and the rhodium clusters from this precursor in toluene. 


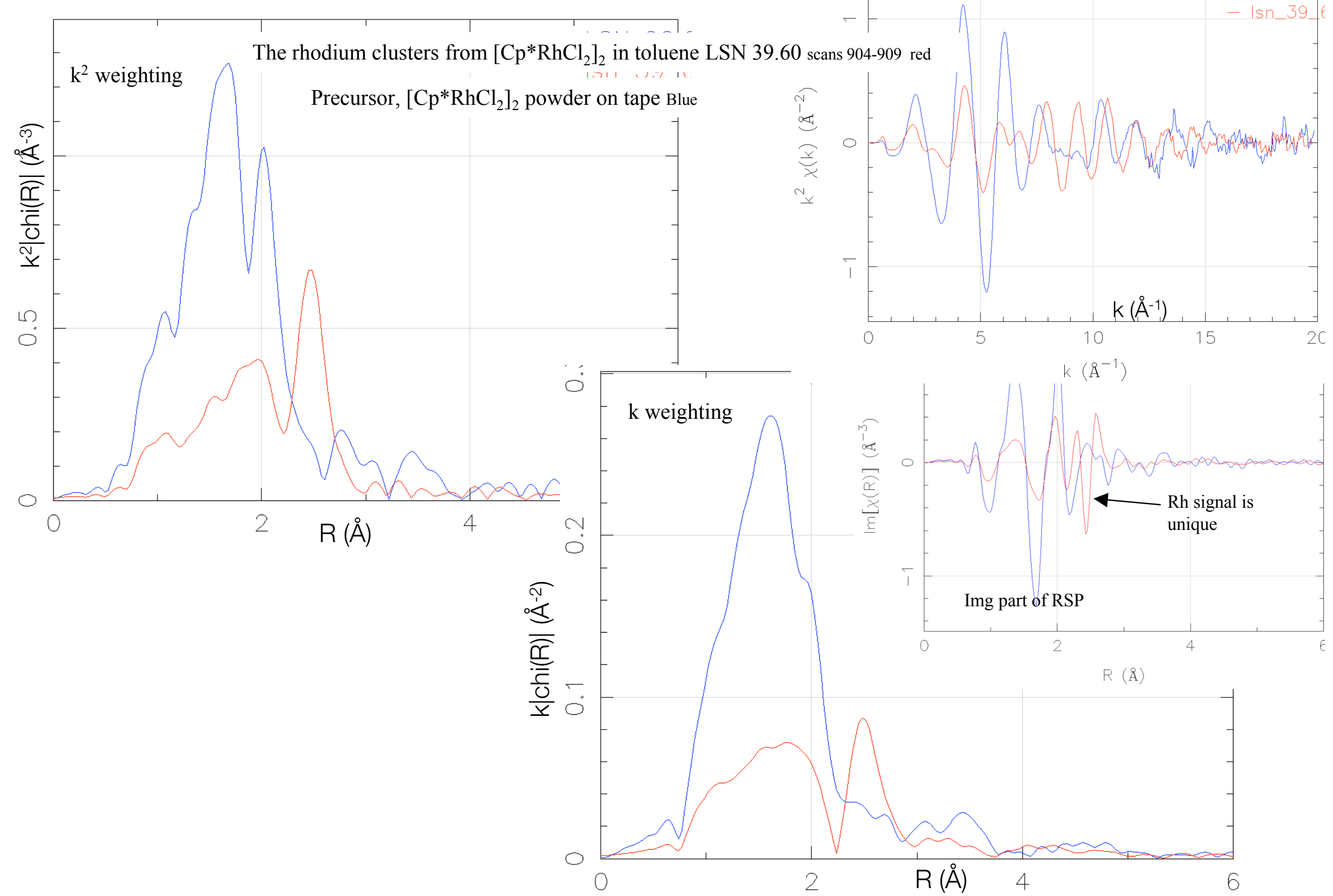

Figure S5. Various XAFS plots for $\left[\mathrm{Cp} * \mathrm{RhCl}_{2}\right]_{2}$ powder and the rhodium clusters from this precursor in toluene. 


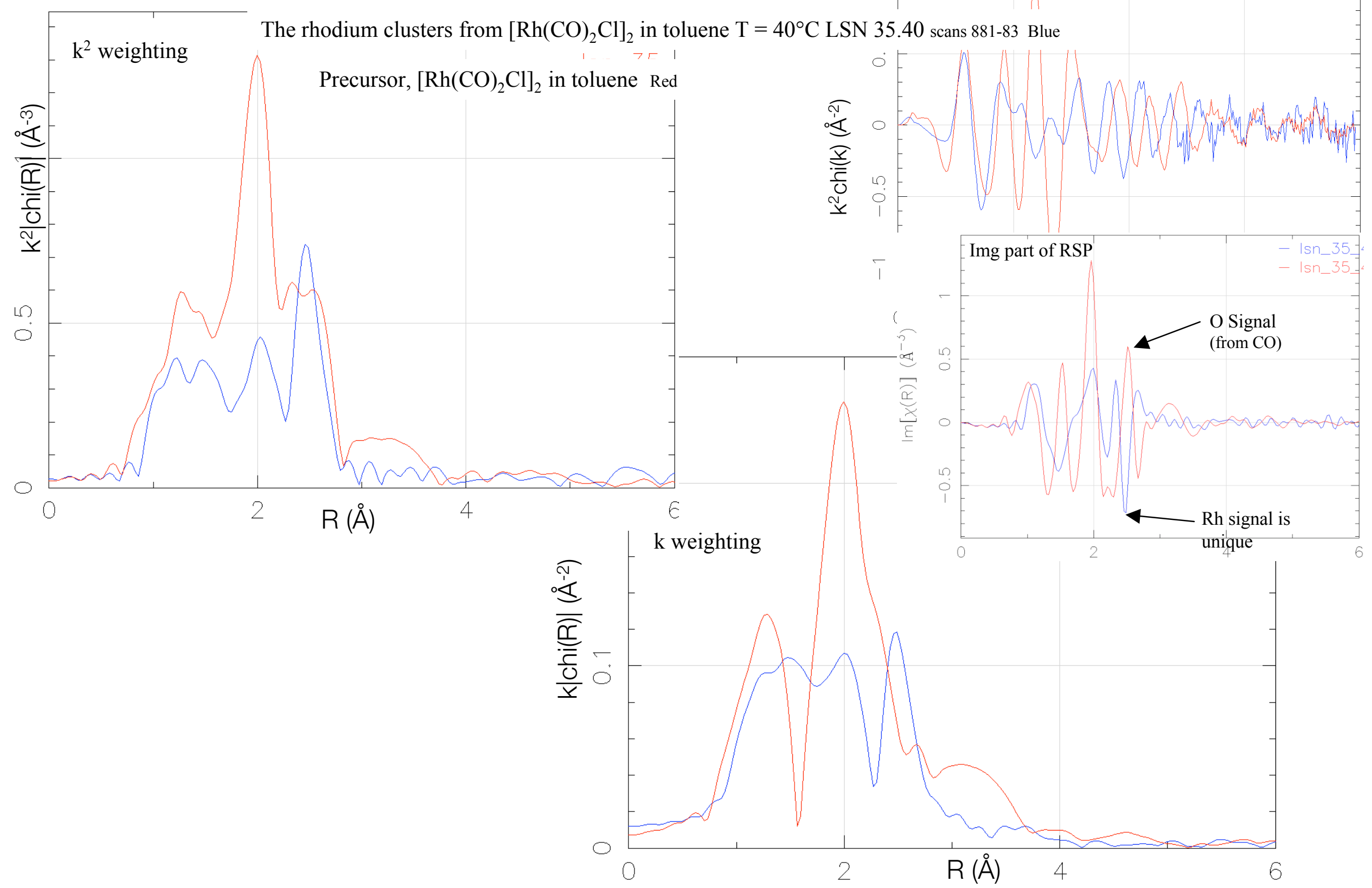

Figure S6. Various XAFS plots for $\left[\mathrm{Rh}(\mathrm{CO})_{2} \mathrm{Cl}\right]_{2}$ in toluene and the rhodium clusters from this precursor in toluene. 


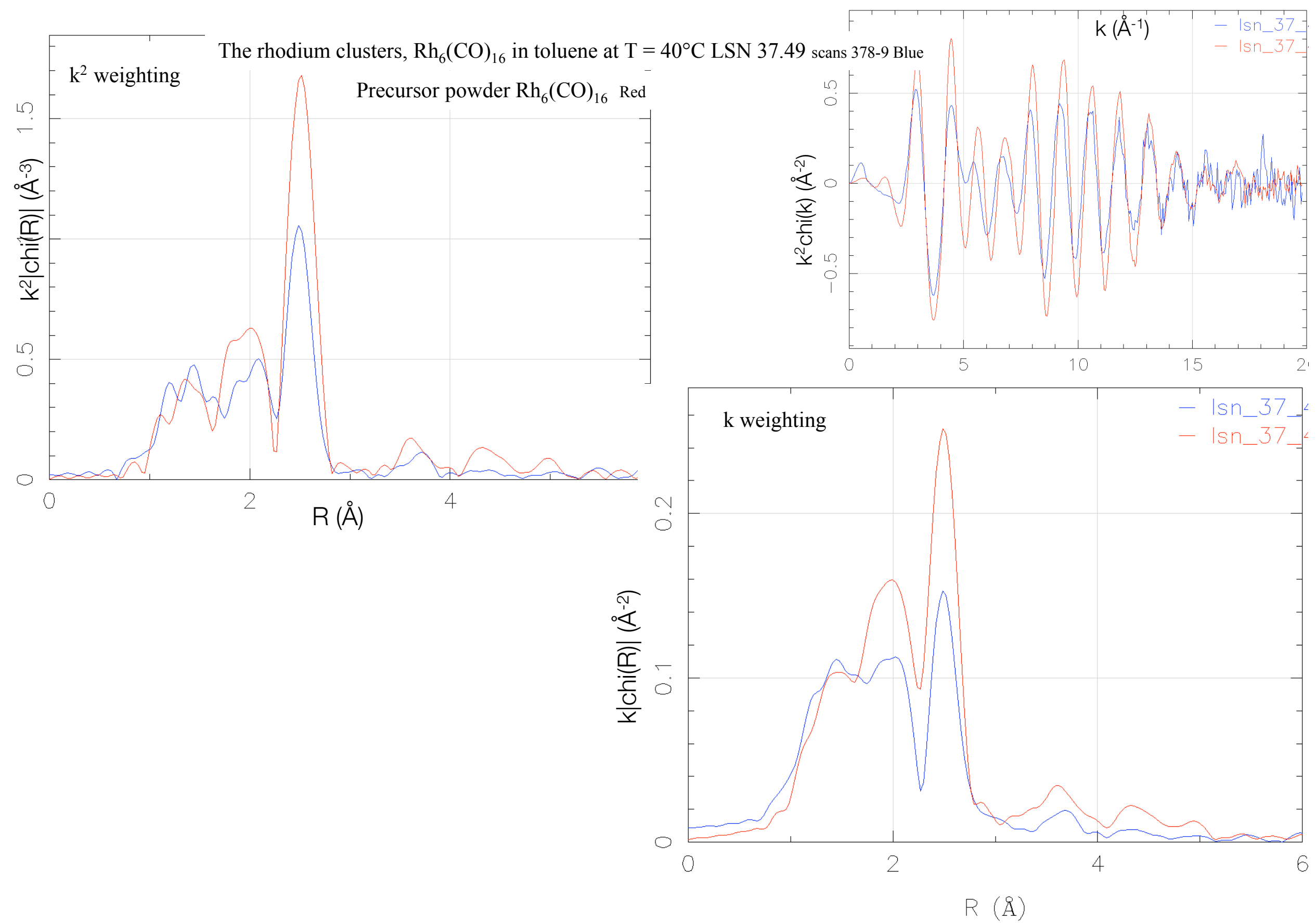

Figure $\mathrm{S} 7$. Various XAFS plots for $\mathrm{Rh}_{6}(\mathrm{CO})_{16}$ powder and the rhodium clusters from this precursor in toluene. 
Figure S8. Various XAFS plots of the theoretical model fit (FEFF8) to $\mathrm{Rh}_{6}(\mathrm{CO})_{16}$ powder spectra.

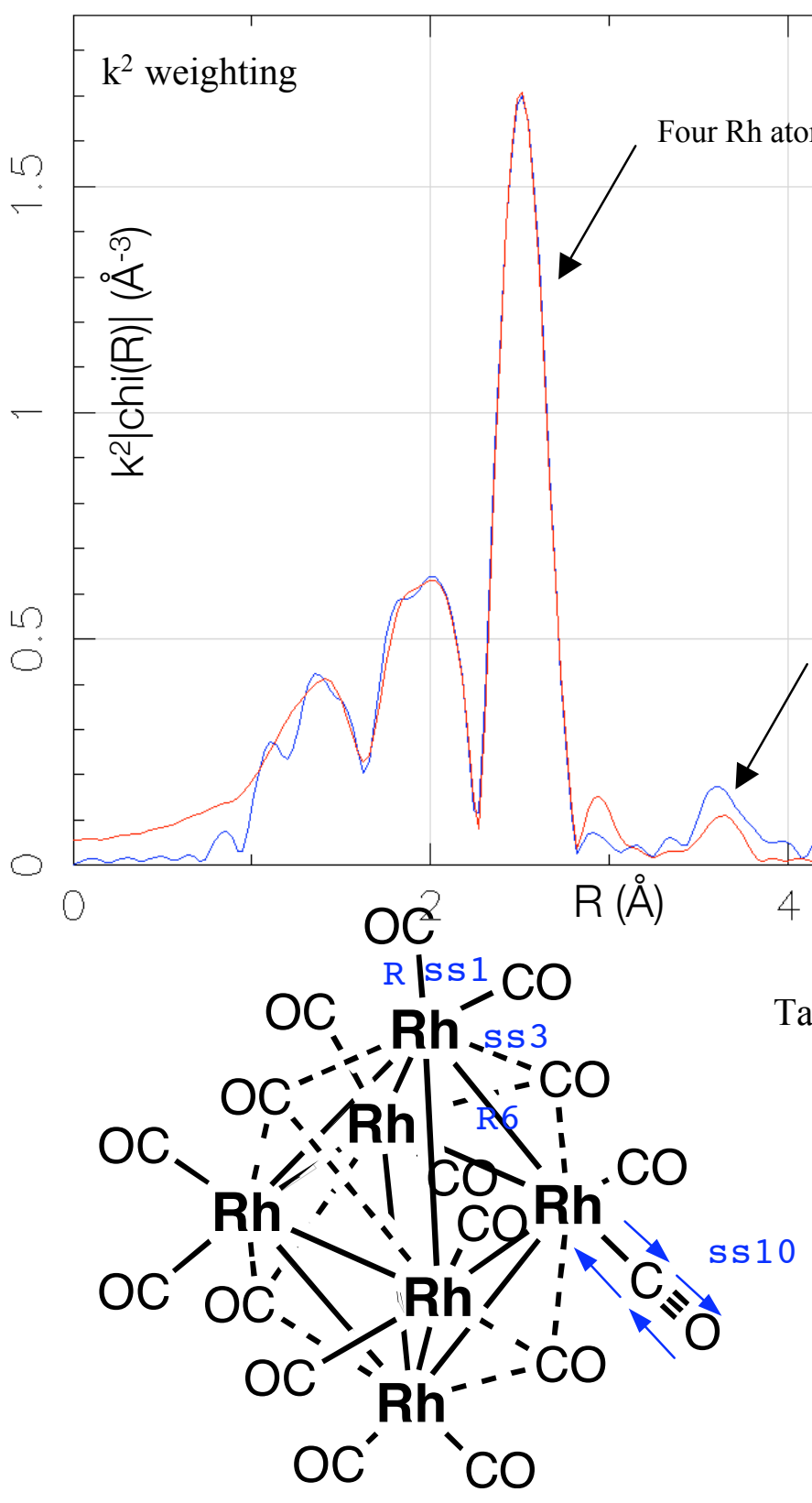

Single $\mathrm{Rh}$ atom at $3.88 \AA$

R6

delr6

ss 1

ss 3

$\operatorname{ss} 6$

$\operatorname{ss} 10$

$\operatorname{ss} 36$

e06
Coordination numbers and starting distances from crystal structure delr $=$ distance deviation from crystal structure
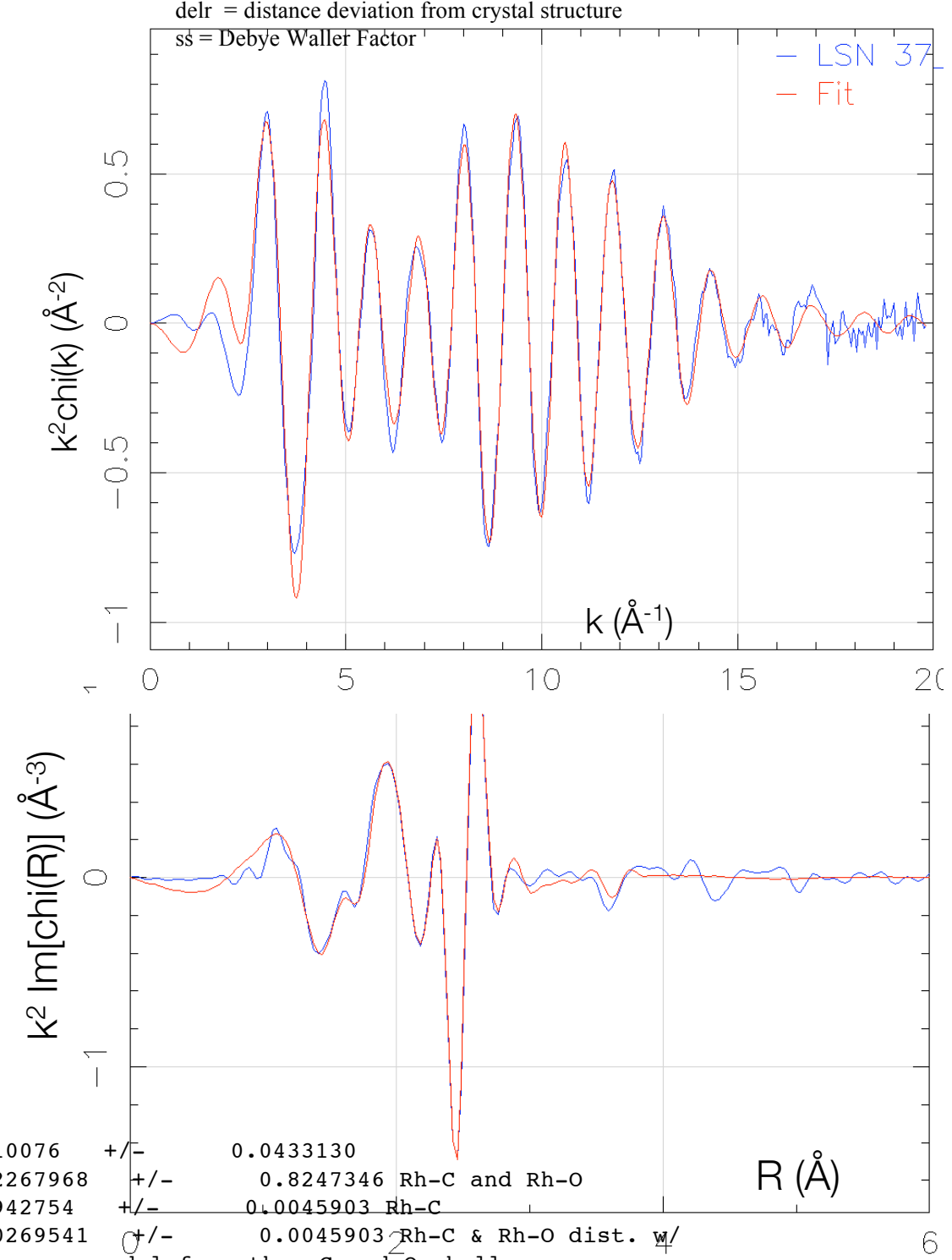

.026954

0.0045903 Rh-C \& Rh-O dist. W/

6

lin. exp.model for other $\mathrm{C}$ and $\mathrm{O}$ shells

$=2.754507+/-\quad 0.0029125 \mathrm{Rh}-\mathrm{Rh}$

$=0.0140073+/-\quad 0.0029125 \mathrm{Rh}-\mathrm{Rh} \mathrm{w} / \mathrm{lin}$. exp.model

$0.0140073+/-$
for other $2 \mathrm{nd}$ Rh distance

$=0.0058366+/-\quad 0.0011914 \mathrm{Rh}-\mathrm{C}$ first shell

$=0.0077324+/-\quad 0.0020440 \mathrm{Rh}-\mathrm{C}$ bridging

$=0.0055675+/-\quad 0.0002523 \mathrm{Rh}-\mathrm{Rh}$ first shell

$=0.0040703+/-\quad 0.0005983 \mathrm{Rh}-\mathrm{C}-\mathrm{O}$ MS 3 paths

$=0.0061594+/-\quad 0.0018050 \mathrm{Rh}-\mathrm{Rh} 2 \mathrm{nd}$ shell

$=-3.8505717+/-\quad 0.7738752 \mathrm{Rh}-\mathrm{Rh}$ 
Figure S9. Various XAFS plots of the theoretical model fit (FEFF8) to $[\mathrm{Rh}(\mathrm{cod}) \mathrm{Cl}]_{2}$ in toluene.

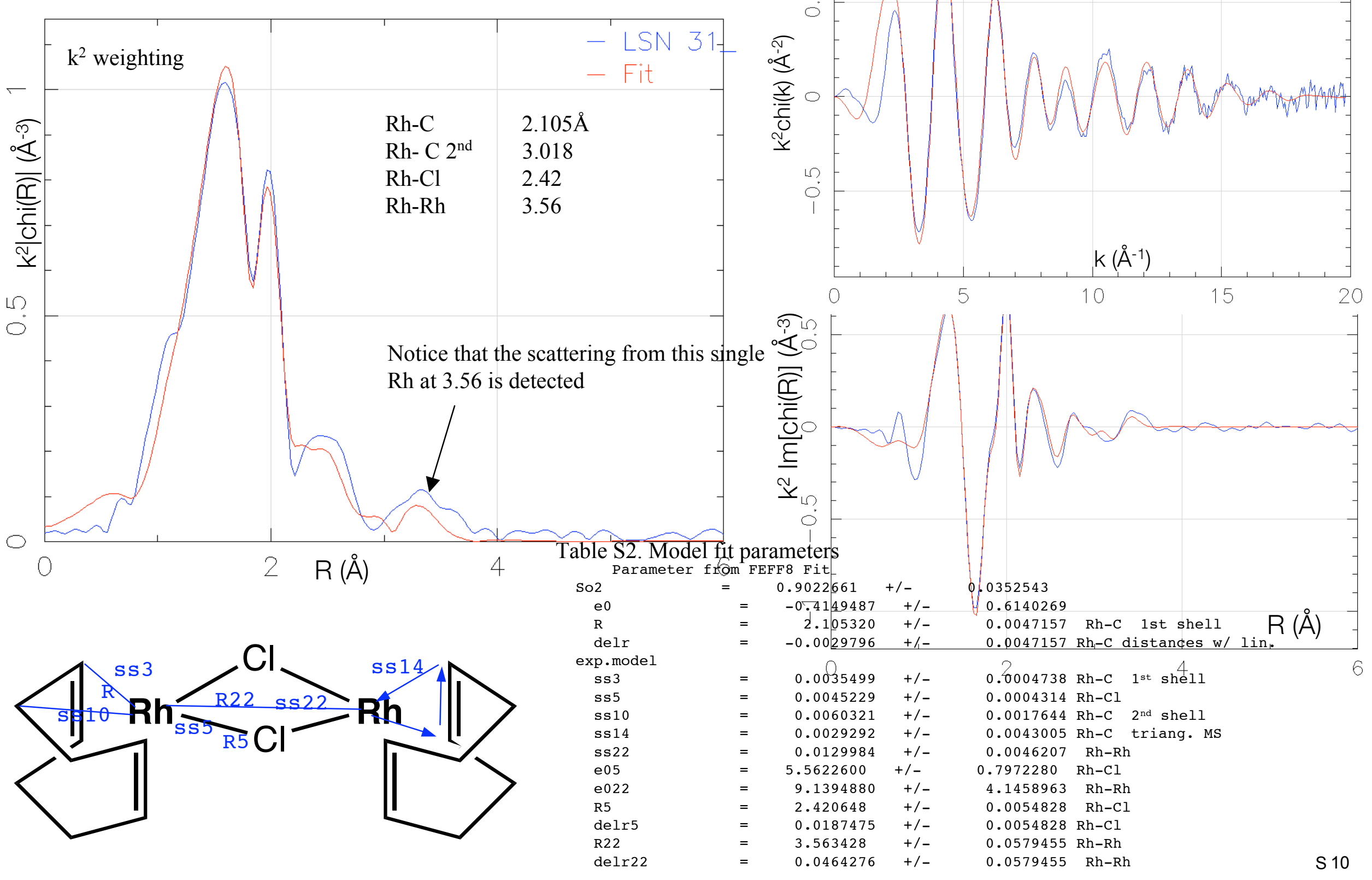


Figure S10. Various XAFS plots of the theoretical model fit (FEFF8) to $\left[\mathrm{Rh}(\mathrm{CO})_{2} \mathrm{Cl}\right]_{2}$ in toluene.

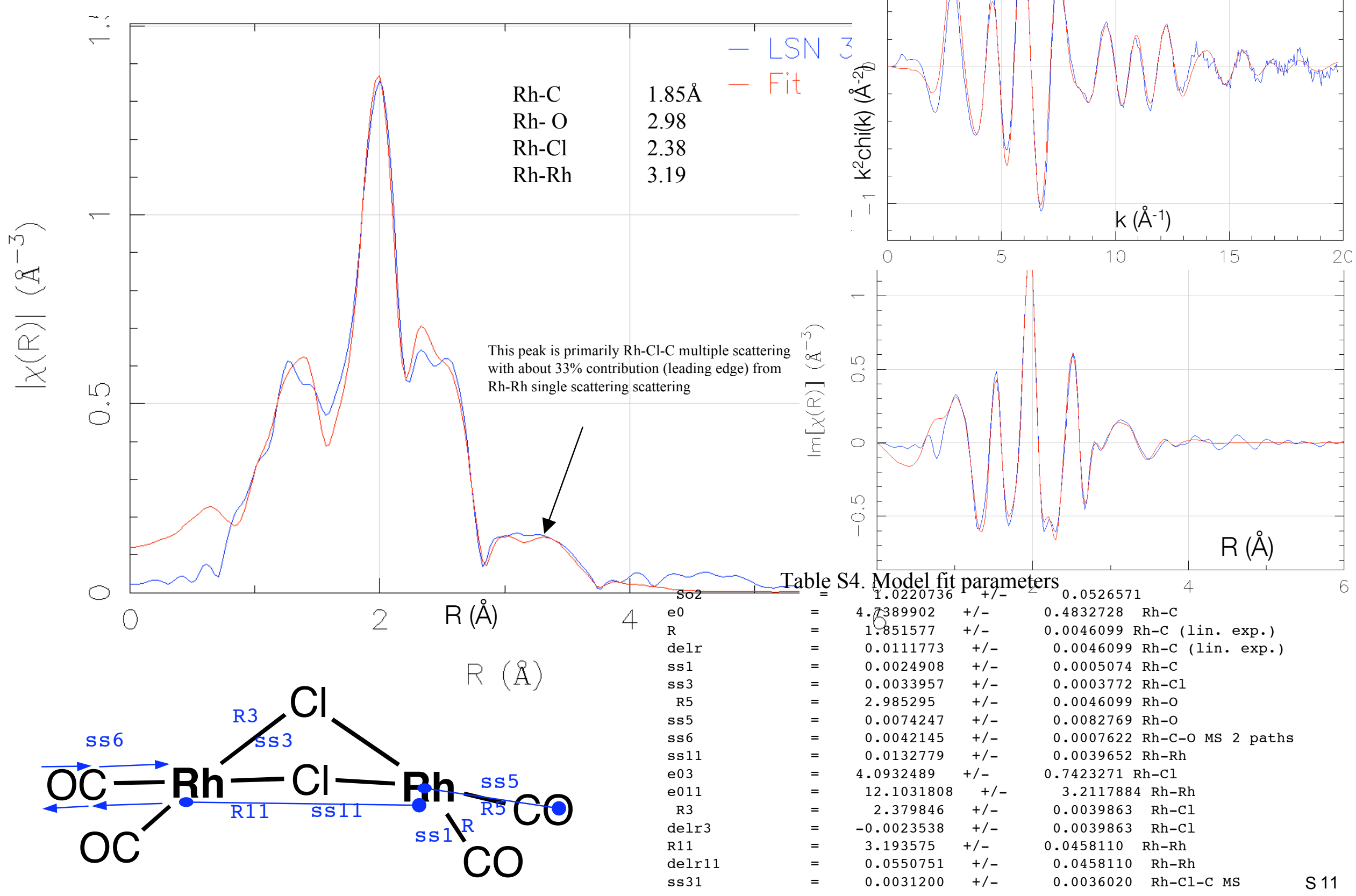


Figure S11. Various XAFS plots of the theoretical model fit (FEFF8) to $\left[\mathrm{Cp}^{*} \mathrm{RhCl}_{2}\right]_{2}$ powder on tape.

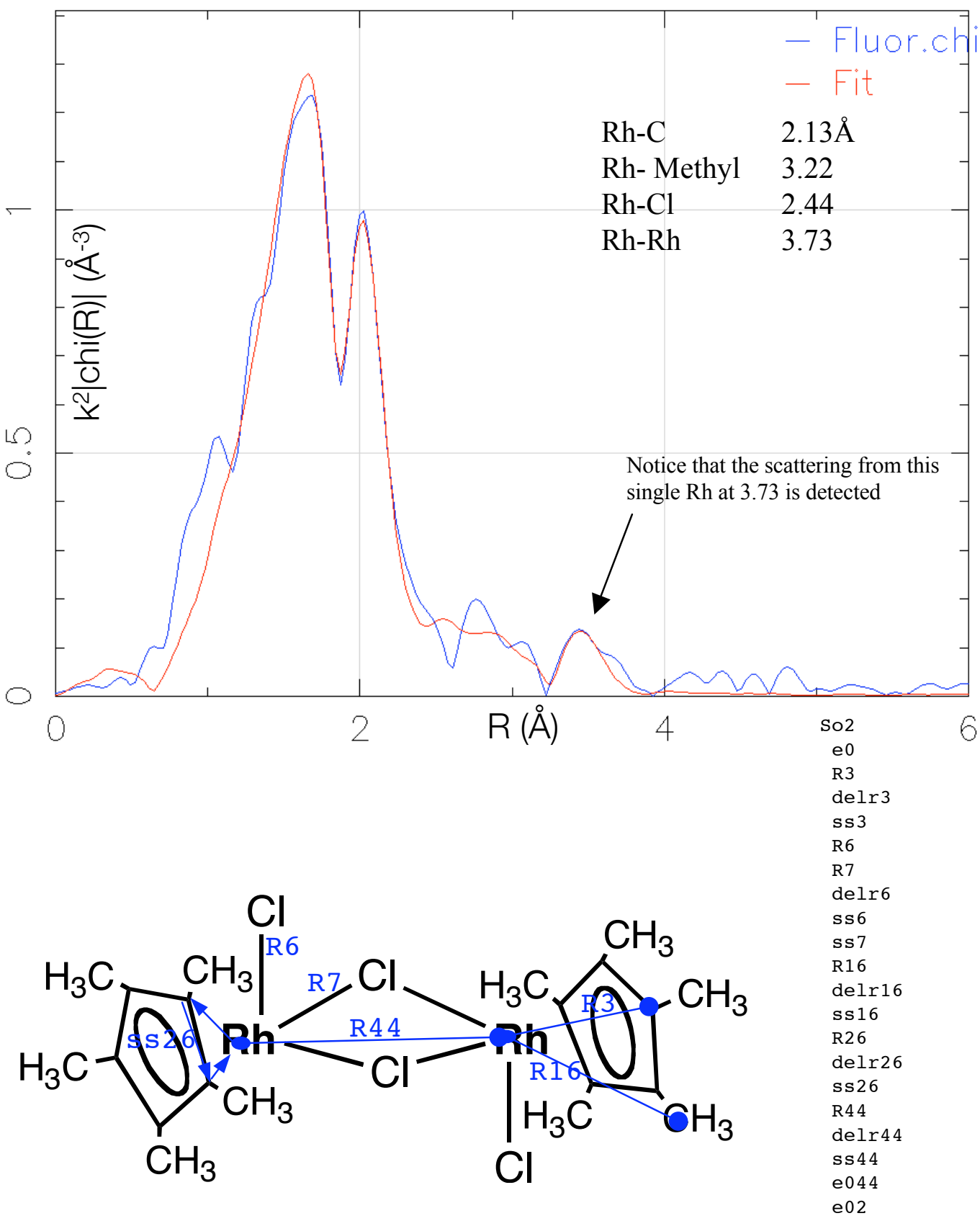

Coordination numbers and starting distances from crystal structure $\mid$ uor ch del $r=$ distance deviation from crystal structure

ss $=$ Debye Waller Factor
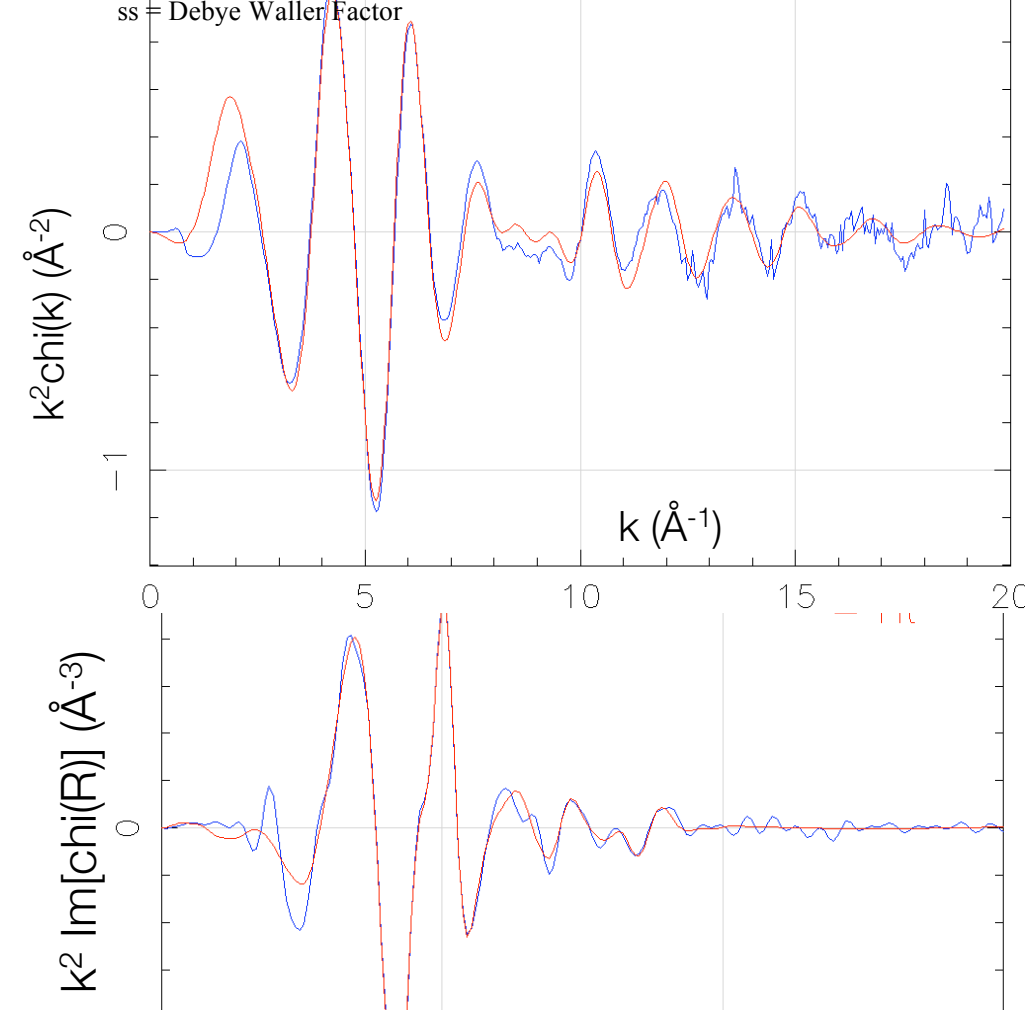

Table S5. Model fit parameters

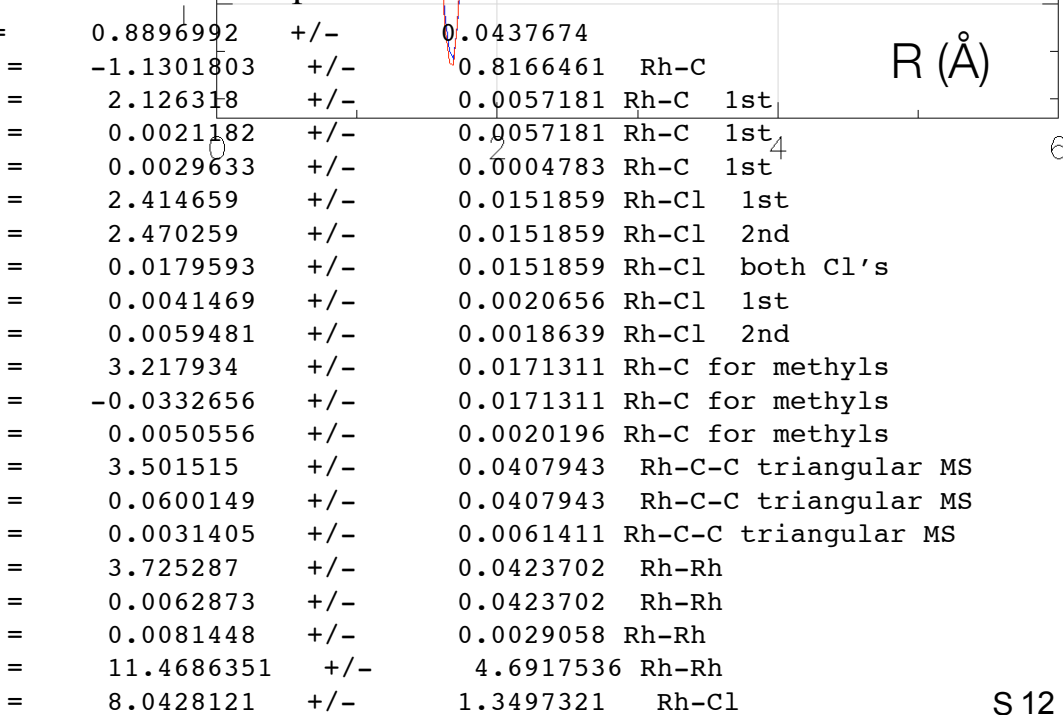


Figure S12. Various XAFS plots of the theoretical model fit (FEFF8) to $\mathrm{Rh}(0)$

metal.

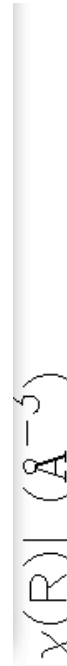

$\omega$

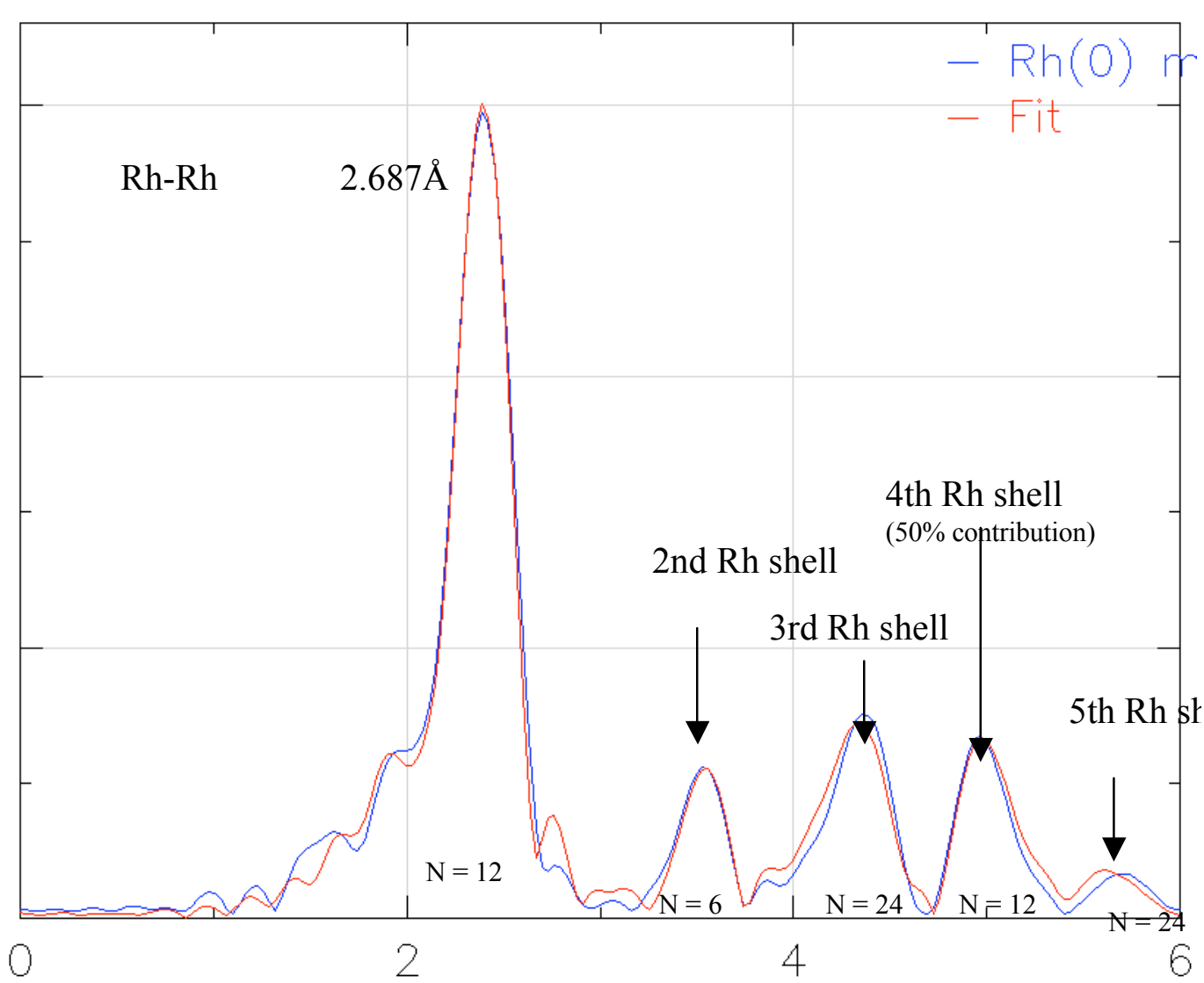

2

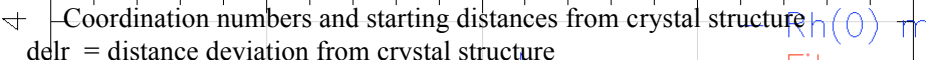
- Fit ss $=$ Debye Waller Factor
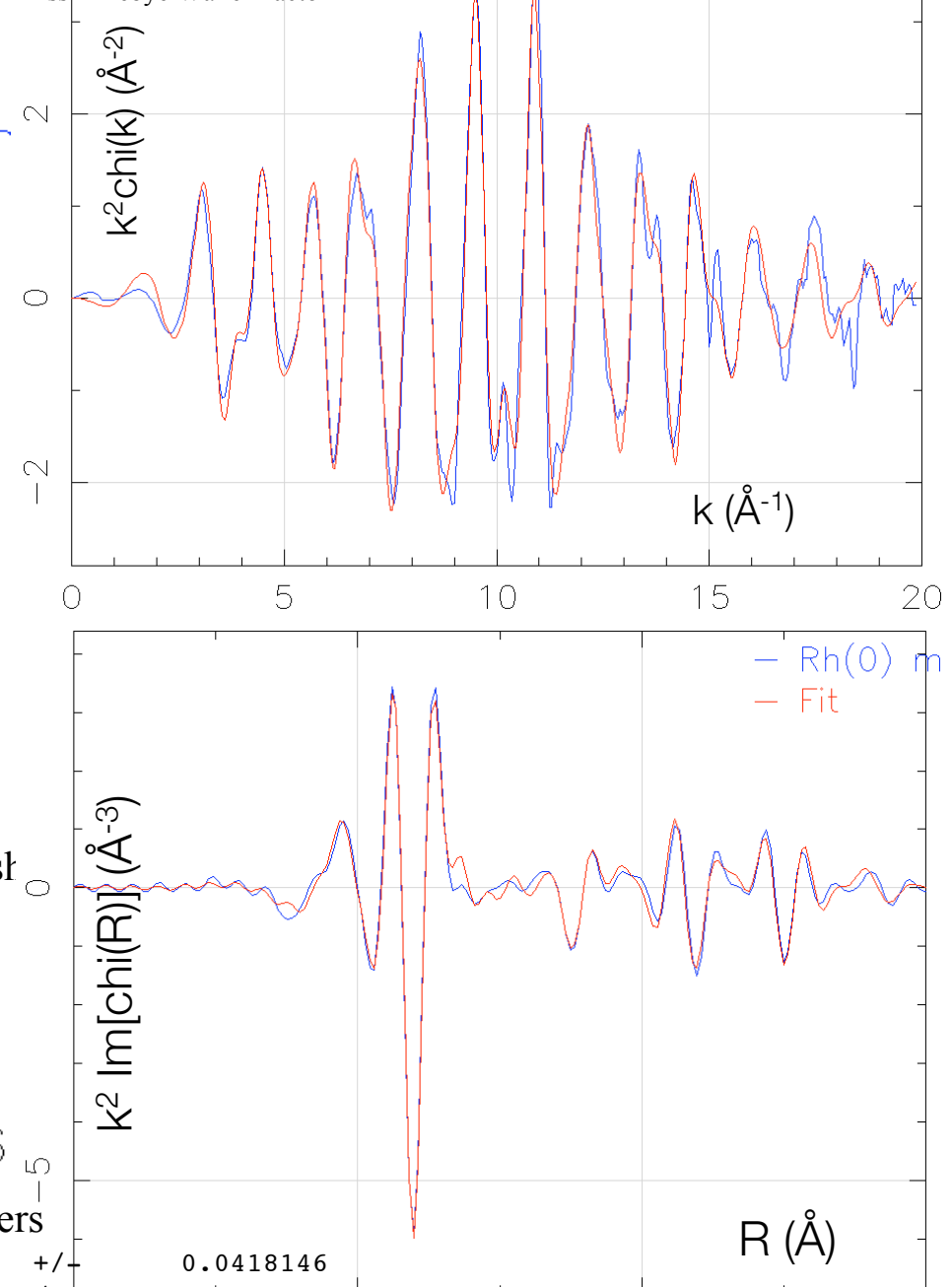

$R(\mathrm{~A})$ so2 e0 $R$

Table S6. Model fit parameters delr

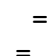

0.8322921 2.7337141 2.686701 $-0.0026994$

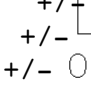

0.4115657

0.0017385

0.0017385 All Rh-Rh distances with

linear expansion model

0.0039375 ne

0.0002226 Rh-Rh first shell $2.68 \AA$

0.0050228

/-

0.0051878

$+1-$

+

0.0035104

$+1-$

$0.0076825+1-$

$0.0065342+/-$

0.0104681

0.0070614

0.0087714
$0.0282306 \mathrm{Rh}-\mathrm{Rh}$ fourth shell $5.38 \mathrm{~A}$

$0.0016037 \mathrm{Rh}-\mathrm{Rh}-\mathrm{Rh}$ triangular path $5.02 \AA$

$0.0111080 \mathrm{Rh}-\mathrm{Rh}-\mathrm{Rh}$ colinear path $5.38 \AA$

$0.0043544 \mathrm{Rh}-\mathrm{Rh}-\mathrm{Rh}$ colinear path $5.38 \AA$

$0.0027593 \mathrm{Rh}-\mathrm{Rh}$ fourth shell $6.01 \AA$

$0.0037470 \mathrm{Rh}-\mathrm{Rh}-\mathrm{Rh}$ triangular path $4.03 \mathrm{~A}$
$0.0005466 \mathrm{Rh}-\mathrm{Rh}$ third shell $4.67 \AA$ 

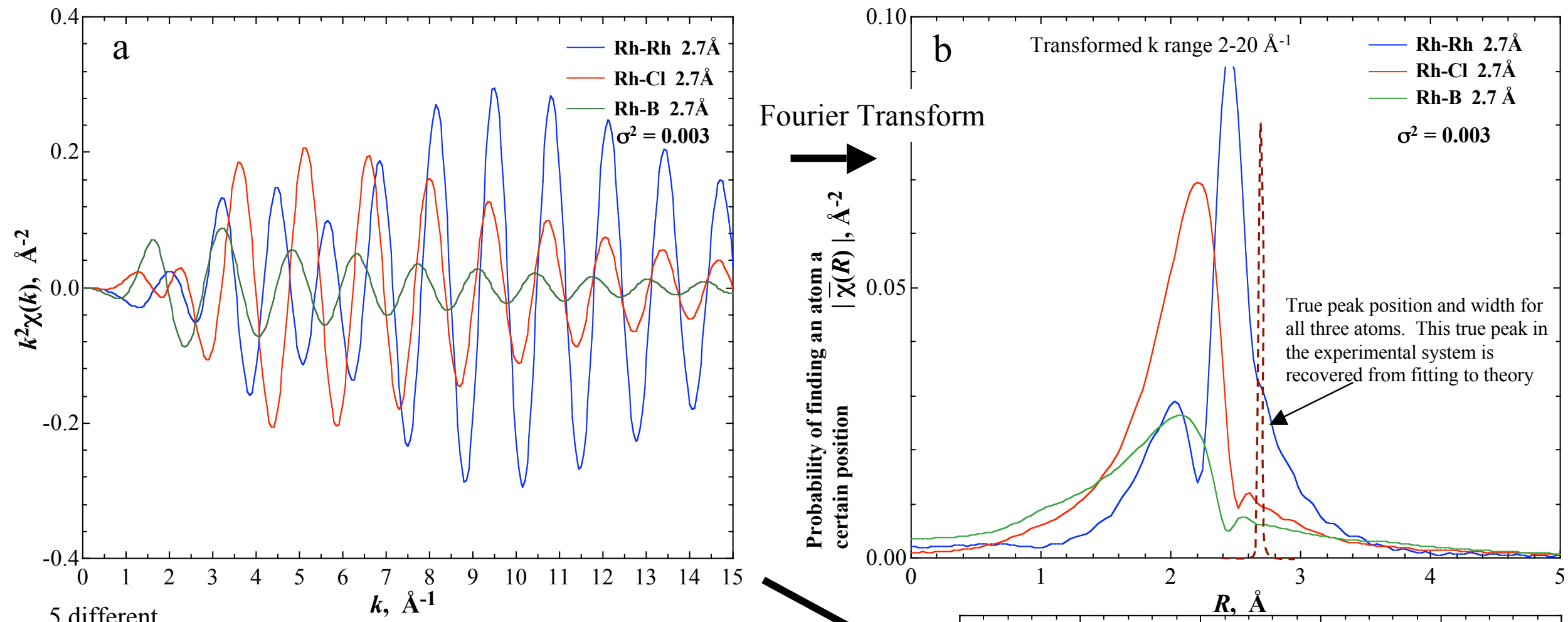

5 different cases explored

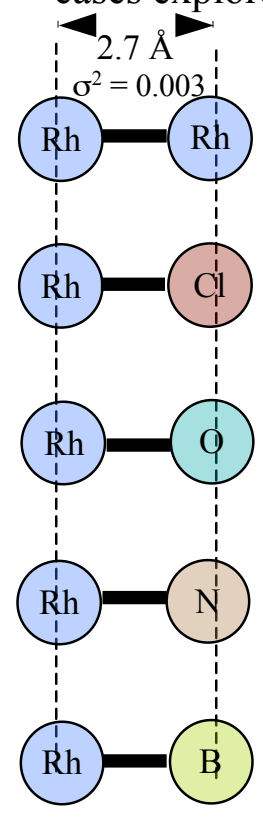

Figure S13. Theoretical scattering (FEFF8) calculations for various first shell atoms about the central $\mathrm{Rh} \mathrm{x}$-ray absorber, including $\mathrm{Rh}-\mathrm{Rh}, \mathrm{Rh}-\mathrm{Cl}$ and $\mathrm{Rh}-\mathrm{B}$ bonds. All atoms are at the same distance and have the same Debye Waller factor $\left(\sigma^{2}=0.003\right)$. In (a), the frequency and amplitude of the oscillations for Rh-Rh scattering are different than those for low $\mathrm{Z}$ atoms, $\mathrm{Rh}-\mathrm{Cl}$ and $\mathrm{Rh}-\mathrm{B}$. In (b) and (c) the patterns for each atom type are unique and they can be calculated exactly using FEFF8. When fitting to experimental data, one fits to both the real and imaginary parts of the FT. This demonstrates that XAFS can be used to discriminate first-shell $\mathrm{Rh}$ atoms from $\mathrm{B}$, $\mathrm{Cl}$ and $\mathrm{N}$ with high accuracy.

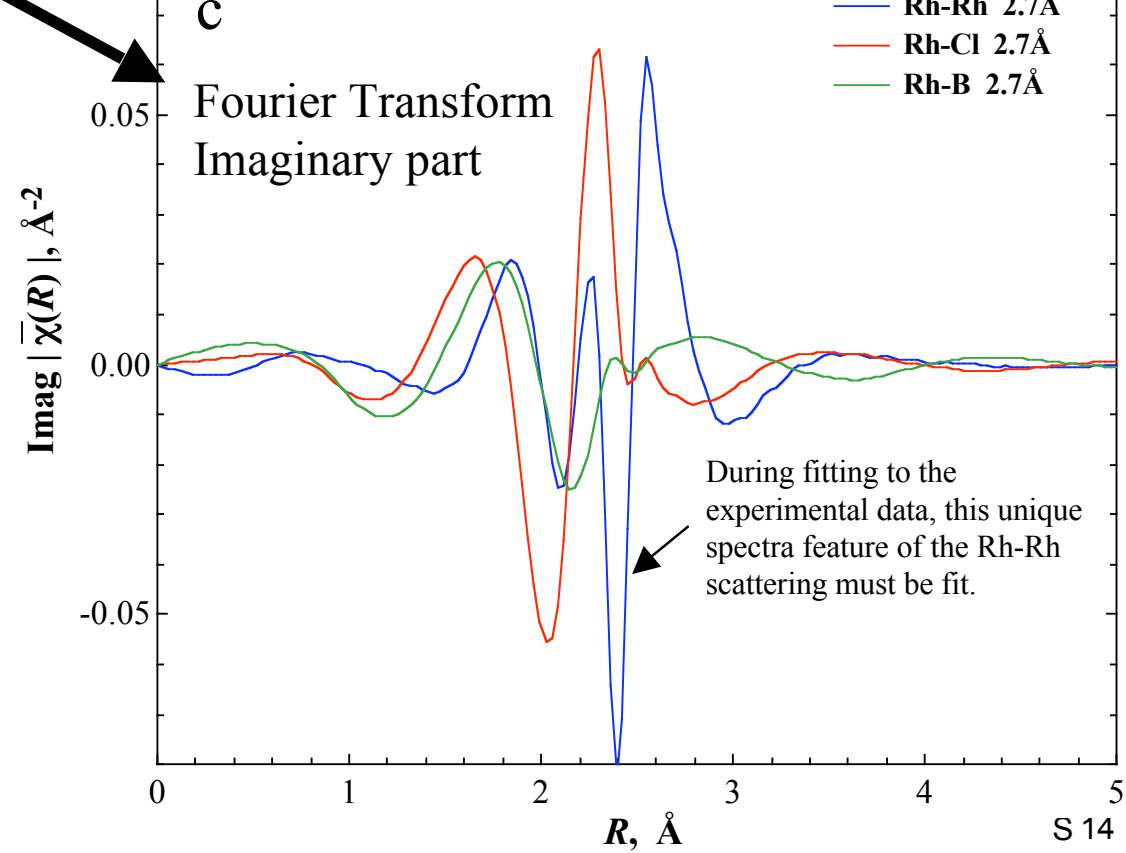




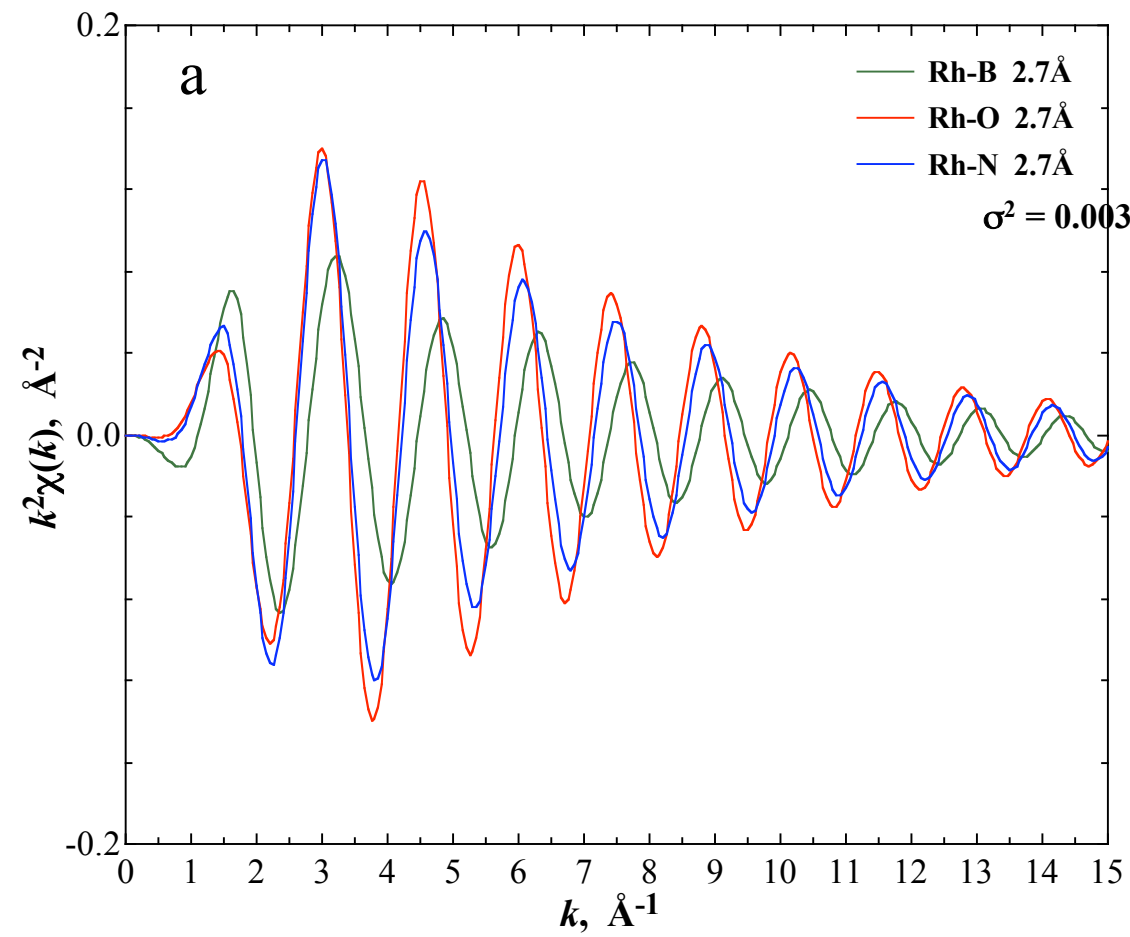

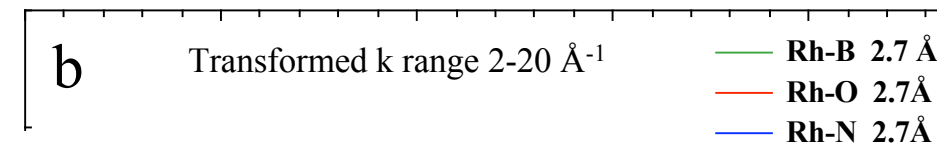

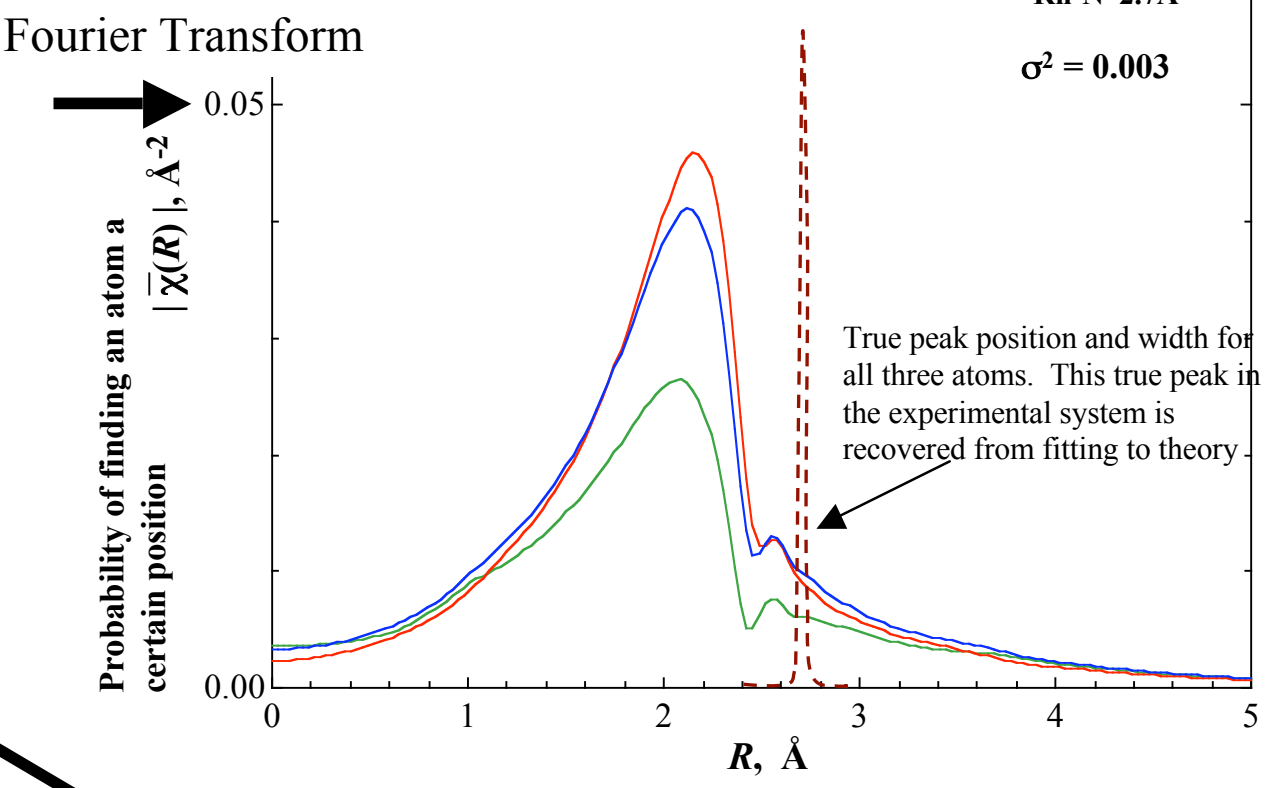

5 different cases explored

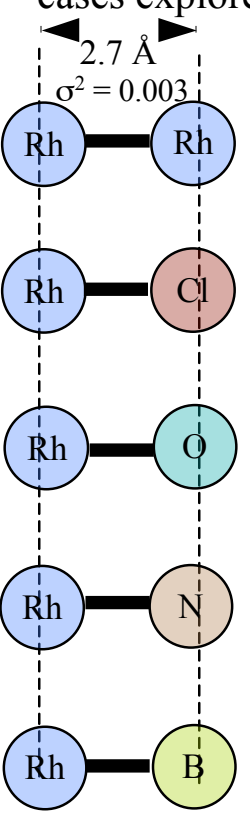

Figure S14. Theoretical scattering (FEFF8) calculations for various first shell atoms about the central $\mathrm{Rh} \mathrm{x}$-ray absorber, including Rh-B, Rh-O and Rh-N bonds. All atoms are at the same distance and have the same Debye Waller factor $\left(\sigma^{2}=0.003\right)$. In $(a)$, the frequency and amplitude of the oscillations for the Rh-B scattering are are slightly different than for Rh-N and Rh-O. In (b) and (c) the patterns for each atom type are different and they can be calculated exactly using FEFF8. When fitting to experimental data, one fits to both the real and imaginary parts of the FT. This demonstrates that XAFS might, in some instances, be used to discriminate Rh-B scattering from $\mathrm{Rh}-\mathrm{N}$.

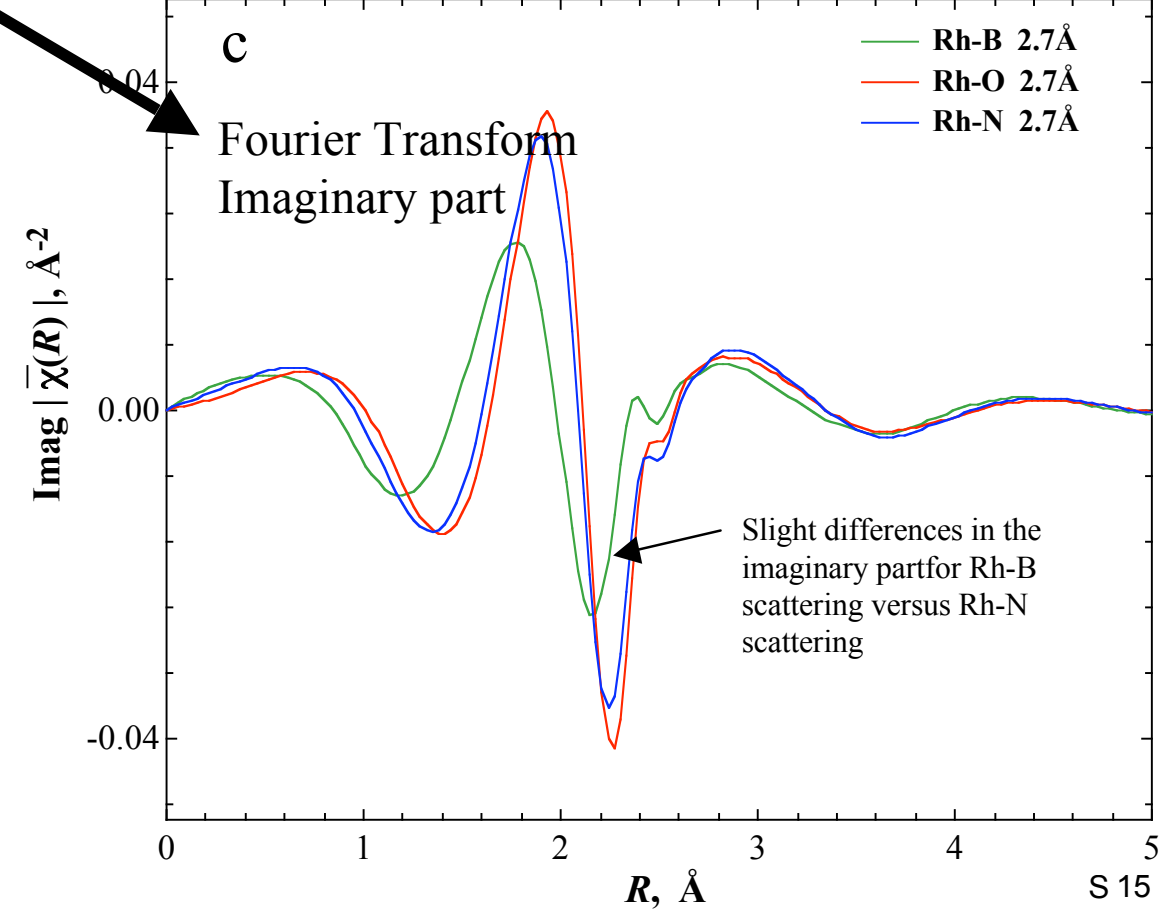

